\title{
The nature of coaching effectiveness with youth soccer players
}

\author{
ALLEN J. SCHUH \\ California State University, Hayward, California
}

\begin{abstract}
An analysis was conducted over 2 successive years on tryout evaluations for 60 males under 8 years of age. Four teams were equated prior to the season. The win-loss-tie records for the season were examined along with the tryout evaluations for the players who advanced to the next age group. Results showed that coaches differed in ability both to train players in the fundamental skills of soccer and to produce a winning team. Coaching effectiveness is not unidimensional; the greatest individual gains in skill were made by players under the last-place coach.
\end{abstract}

What is coaching effectiveness when one is dealing with very young players? One measure of coaching effectiveness could be a team's win-loss-tie record. A good coach, by an alternative interpretation of coaching effectiveness, could be one who takes players at a given level of development and trains them to a higher level. The skill levels of players build and carry on for all future years of participation. The win-loss record of the team is for that season only.

\section{METHOD}

\section{Participants}

The coach participants were four adult males who were appointed by the local youth soccer association to duties as head coaches of upperhouse soccer teams comprising players of under 8 years of age. Coaching assignments at this level are given only to coaches whose qualifications are well known to the local coaching coordinator. All coaches had had several years' coaching and refereeing experience.

The player participants were 60 males, under 8 years of age, who participated in tryouts and were assigned to upperhouse teams. Of approximately 142 males in the geographical area who were eligible because they had played at least 1 year of league soccer, 80 were evaluated at the under- 8 age-group tryouts. The following year, 115 of the 390 males who were eligible were evaluated at the under-10 age-group tryouts.

In addition to the upperhouse teams, two competitive teams were formed. Competitive teams were composed of those players who had qualified for upperhouse teams but whose families intended to make a substantially greater financial and time commitment to soccer than the parents of players on the upperhouse teams. The tryout ratings for players who were appointed to the competitive teams were considered confidential by the local youth soccer association and were not available for analysis.

\section{Evaluation Procedure}

Upperhouse tryouts for youth soccer players are the standardized opportunity to evaluate player capacities in fundamental skills and in field trial situations. The evaluations are conducted in the spring of the year after all house league and competitive season activities have been completed. All youths recommended by their coaches for the tryouts are assembled for $10 \mathrm{~h}$ of evaluation on soccer skills: passing, trapping,

Inquiries or requests for reprints should be sent to Allen J. Schuh, Department of Management Sciences, School of Business and Economics, California State University, Hayward, CA 94542. dribbling, kicking, heading, fakes, fair shoulder charge, tackling, throwins, and the separate goalkeeper skills of ballhanding and punting (Chyzowych, 1978). Evaluations are conducted by experienced coaches using standardized evaluation forms. Basic skill trials are conducted for $2 \mathrm{~h}$ for each of 2 days, and field trials are conducted for $2 \mathrm{~h}$ for each of 3 days. Players are assigned a final rating composed of the simple sum of all inputs on a 5-point scale divided by the number of inputs. The estimated reliability of the ratings by the split-half method (Guilford, 1954) was .66. These ratings were used to assign players to teams such that all teams were equated for talent level before the season began. Players participating in the under- 8 tryouts were ranked by their overall suitability rating. The ranks were assigned to the four teams within blocks of four. Coaches picked the ranks assignment out of a hat on each round. On cleanup, the lists were examined to ensure that the coach's son (if participating) was assigned to his team and that brothers were assigned to the same team. The sum of ranks was $38,37.5,38.5$, and 36 , respectively, for Teams 1 to 4 . Friedman's analysis of variance by ranks (Siegel, 1956) was not significant for the teams $\left(\chi_{\mathrm{r}}^{2}=.14\right)$.

The evaluation of coaching effectiveness on the criterion of ability to develop individual player skills was by a comparison of the players' overall suitability ratings at the under- 10 tryouts against the year-earlier ratings at the under- 8 tryouts. A related indication of effectiveness is the number of players the coach recommended for advancement to play upperhouse in the older age group. A coach should develop all players assigned to his team in their individual skills and be willing to have his peers see their developed skills at the tryouts.

Coaching effectiveness can also be evaluated by the ability to produce a winning team. Since every effort was made to equate players' skill levels on teams before the season, any real differences among the coaches should have resulted in differential win-loss-tie records at the end of the 13-game season. Each of the four teams played each other four times; then there was a position round in which the top two and the bottom two teams in the standings played each other. The fields, ball, weather, and referees were held constant or controlled. The time of day of games was counterbalanced. If all coaches were equal in ability, then all teams should have had the same win-loss-tie record at the end of the season.

\section{RESULTS}

The win-loss-tie records for the coaches were: Coach 1-10-0-3 (23 points); Coach 2-6-6-1 (13 points); Coach 3-3-6-4 (10 points); and Coach 4-2-9-2 (6 points). (Two points are awarded for a win and one point for a tie.) The Kuder-Richardson Formula 21 reliability estimate (Guilford, 1954) for the team standings was .868, with a standard error of measurement of 2.636 points. 
There were real differences among the coaches in their abilities to produce winning teams.

An alternative criterion of coaching effectiveness was defined as the ability of the coach to improve individual player skill levels such that the player (if qualified by age and geographical area) would be recommended for and pass the under-10 upperhouse tryouts held at the beginning of the following season. The proportion of players recommended for and passing advancement to either the competitive team or the upperhouse was significantly different for the coaches. A chi-square test (Siegel, 1956) yielded a value of 8.776 , which was significant at the .05 level. The associated contingency coefficient was .371 . Coach 1 produced 13 players who were recommended for and passed the under-10 upperhouse tryouts. One player moved, and one failed the under-10 tryouts. Coach 2 recommended only 4 players, and 1 additional player was appointed to a competitive team. One player moved, and 2 players stayed at under-8s. Coach 3 recommended 7 players, and 2 went to a competitive team. One player failed in the under- 10 tryouts. Coach 4 recommended 8 players, who all passed. One player stayed at under-8s. One player was put on a competitive team. Since the overall chi-square was significant, the observed and expected frequencies were examined. Coach 1 had substantially more players succeed, whereas Coach 2 had substantially fewer, which accounted for most of the variance in the success rates.

An analysis was made of the difference between tryout scores at the under- 8 and under- 10 age levels for the same players. The scores tend to drop because evaluation is considerably more demanding at the under- 10 level. The only three exceptions to the drop in scores all occurred with Coach 4. One player received the same evaluation, and two players actually received higher evaluations at the under-10 level. Not a single one of the other players who played for the other three coaches received a higher evalu- ation. The Fisher (Siegel, 1956) exact probability for this result is .012 . The average difference scores between under- 8 and under-10 tryouts for Coaches 1 to 4 were, respectively, $-.388,-.475,-.627$, and -.233 . Of interest is that Coach 4 , who developed his players the most in fundamental skills, had the worst win-loss record. Coaching effectiveness is not unidimensional.

\section{DISCUSSION}

Coaches started the season with teams equated on playing ability, but the coaches differed substantially in their abilities to put together winning teams. The coach whose team won the most games did produce players who advanced in fundamental soccer skills, but he was not the coach who produced the most gain or the most dramatic individual increases. Clearly, then, coaching success is not unidimensional. The puzzle in these data is why Coach 4 should have had several players make more dramatic skill improvements than even the first-place coach. The author observed these coaches' practices and games on many occasions and, on reflection, can suggest that what Coach 4 did was to try to make soccer fun for his players. One can wonder how the players for Coach 4 may feel in later years about playing. Perhaps because of their increased skill levels, they will still want to play, whereas those from Teams 2 and 3 , who lacked the training Coaches 1 and 4 provided, may not. The second- and third-place coaches produced neither the team with the most wins nor the players with the greatest increases in skill levels. The crux of this paper is that no one would seriously consider Coach 2 or 3 to be a better coach than Coach 4 .

Providing feedback to the coaches, parents, and soccer authorities on how well the coaches did in developing their teams' skill levels could create an awareness that there is more to coaching youth soccer players than producing this season's win-loss record.

\section{REFERENCES}

CнYzowych, W. (1978). The official soccer book of the United States Soccer Federation. Chicago: Rand McNally.

Guilford, J. P. (1954). Psychometric methods. New York: McGraw-Hill.

SIEGEL, S. (1956). Nonparametric statistics for the behavioral sciences. New York: McGraw-Hill.

(Manuscript received for publication May 29, 1984.) 